\title{
An alternative retractor for transcervical thymectomy
}

\author{
Christopher B. Komanapalli, MD, Thomas D. Person, MD, Paul Schipper, MD, and \\ Mithran S. Sukumar, MD, Portland, Ore
}

$\mathrm{T}$ ranscervical thymectomy has had a significant effect on the surgical treatment of patients with myasthenia gravis. It has decreased patient morbidity and increased patient satisfaction. The Cooper retractor (Pilling Company, $\mathrm{Ft}$ Washington, Pa) allows for visualization of the anterior mediastinum and makes the transcervical approach feasible. ${ }^{1}$ However, this specialized retractor is difficult to obtain. We propose the use of the Rultract Skyhook retractor (Rultract, Inc, Independence, Ohio), which is versatile, economical, and as effective.

\section{Technique}

The Rultract Skyhook system (Figure 1) is traditionally used for internal thoracic artery dissection, redo sternotomies, and subxiphoid pericardial procedures. This system involves several parts that are critical to its design. The retractor post, which connects the system to the bed, attaches to a rotating extender bar, which allows increased degrees of freedom in movement and placement of the retractor (Figure 1). The ratchet (Figure 2, A) can be attached to various sizes and types of retracting rakes, including a dual arm retractor (commonly used for thoracic artery harvest; Figure $2, B$ and $C$ ) or a suprasternal rake used for a transcervical thymectomy (Figure 2, D). This creates a versatile system that can be adjusted to a particular patient without greatly changing the efficacy of the retractor.

Although the Cooper retractor is a robust retracting system able to hold weight exceeding that of the Rultract Skyhook retractor, the Rultract retractor enables surgeons to perform transcervical thymectomy in the majority of patients. The rotating extender bar, post, and ratchet, when positioned appropriately on the operating room table, have a static weight capacity of up to $300 \mathrm{lbs}$. The ratchet, however, when used for lifting the chest (while the remainder of the body is supported by the operating room table), is only rated at $80 \mathrm{lbs}$. This is sufficient for the majority of patients who undergo this procedure. We have successfully performed this procedure with the Rultract retractor in a patient weighing $220 \mathrm{lbs}$.

The Rultract Skyhook retractor also is backward compatible with previous Rultract retraction systems, and parts are interchangeable with previous systems. In effect, if all one needs is the ratchetrake component to add to their existing system, it can be purchased separately. The versatility of the Rultract Skyhook retractor in pro-

From the Department of Surgery, Division of Cardiothoracic Surgery, Oregon Health and Science University, Portland, Ore.

Received for publication Oct 4, 2004; accepted for publication Nov 4, 2004

Address for reprints: Mithran Sukumar, MD, OHSU Division of Cardiothoracic Surgery, Mailcode: L353, 3181 SW Sam Jackson Park Rd, Portland, OR 97239 (E-mail: sukumarm@ ohsu.edu).

J Thorac Cardiovasc Surg 2005;130:221-2

$0022-5223 / \$ 30.00$

Copyright $\odot 2005$ by The American Association for Thoracic Surgery

doi:10.1016/j.jtcvs.2004.11.039 viding exposure in both cardiac and thoracic surgical procedures makes it an economical option for smaller centers using one retracting system.

Further exposure of the thoracic inlet is facilitated by fish hook-type subplatysmal flap retractors. ${ }^{2}$



Dr Sukumar

\section{Conclusion}

The cost and difficulty of purchasing a specific retractor for just one procedure has possibly limited transcervical thymectomy as a technique for resecting the thymus gland in patients with myasthenia gravis. The Rultract Skyhook retractor affords a cost savings because of its versatility in providing exposure for both cardiac and transcervical thymectomies, as well as its interchangeability with previous systems. In summary, we propose the Rultract Skyhook retractor as an equally efficacious device to allow adequate surgical exposure to perform a transcervical thymectomy.

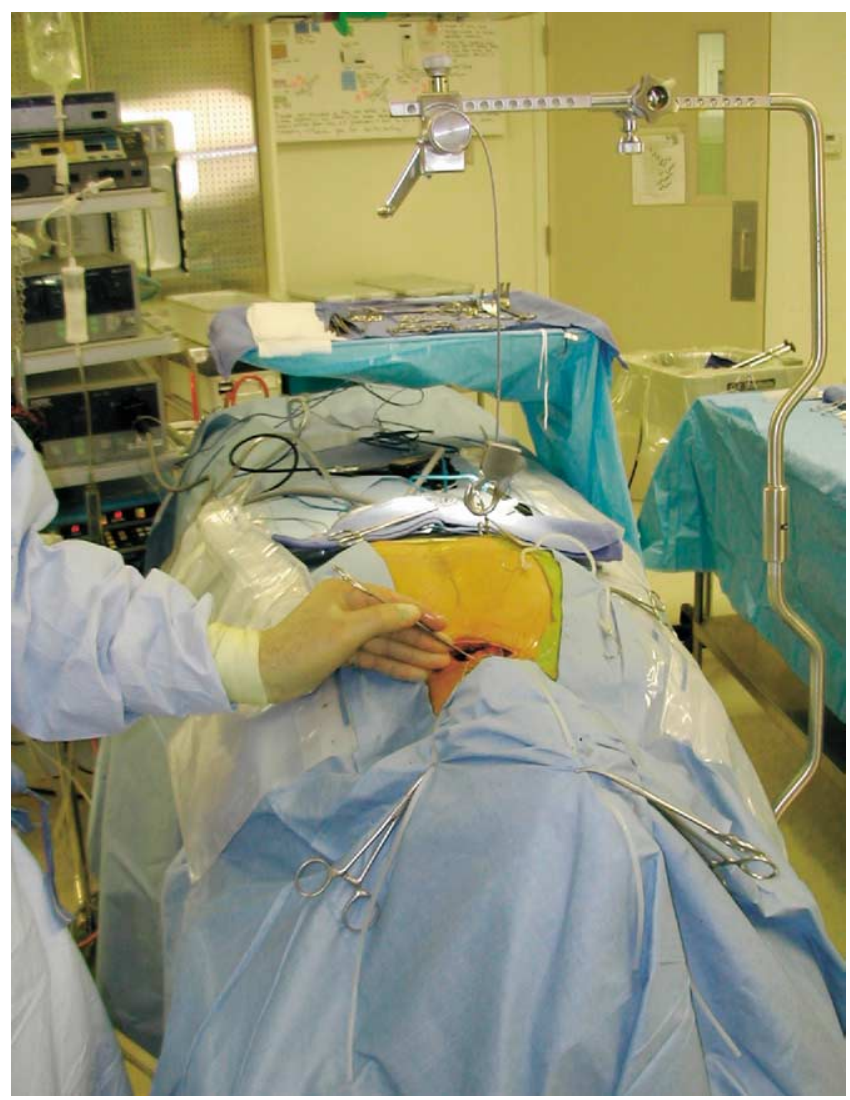

Figure 1. Spline post and rotating bar are easily attached to the operating room table. 

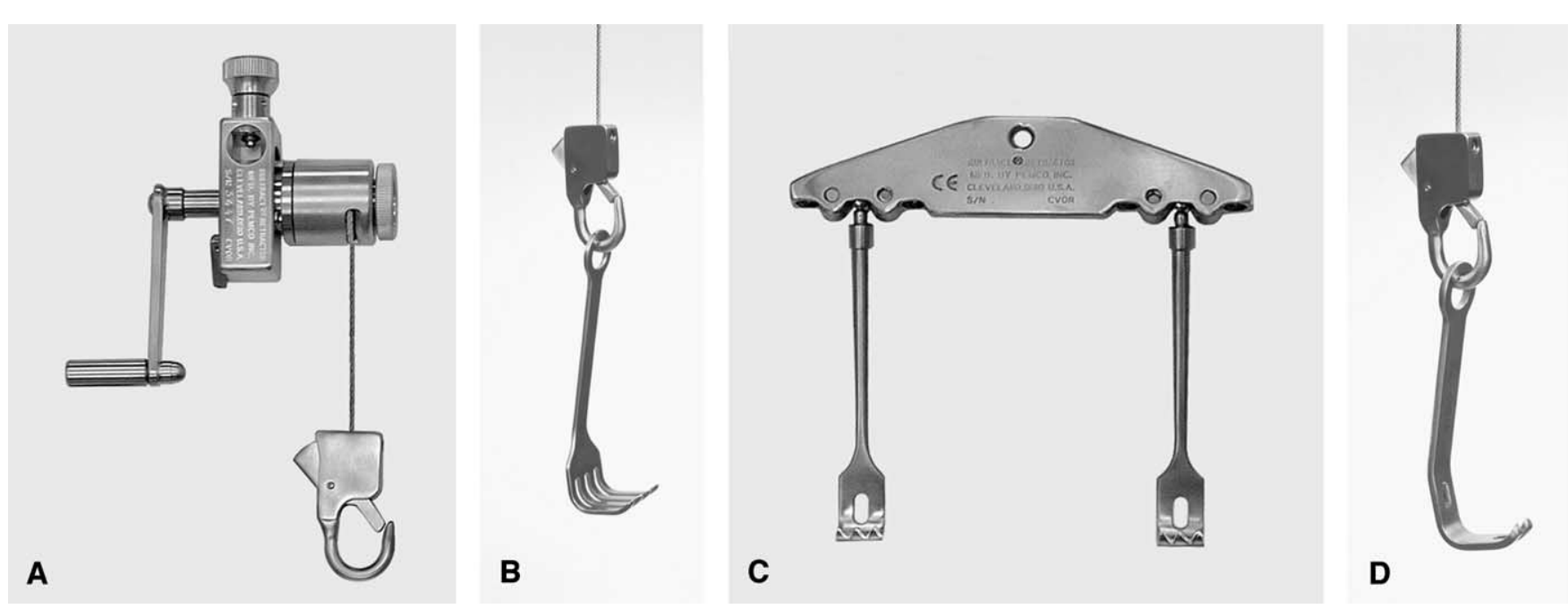

Figure 2. Winch elevating system (A). Multiple retracting hooks (B, C, D) available for different retraction needs. Retractor (D) used for transcervical thymectomy.

\section{References}

1. Cooper JD, Al-Jilaihawa AN, Pearson FG, Humphrey JG, Humphrey HE. An improved technique to facilitate transcervical thymectomy for myasthenia gravis. Ann Thorac Surg. 1988;45:242-7.
2. Arullendran P, Robson AK. The fish hook retractor. J Laryngol Otol. 2001;115:212-3. 